\title{
Increased Incidence of Type 1 Diabetes in Children and No Change in the Age of Diagnosis and BMI-SDS at the Onset - is the Accelerator Hypothesis not Working?
}

\author{
(D) Barbara Wasyl-Nawrot1,2, (1) Małgorzata Wójcik2,3, (D) Joanna Nazim²,3, (D) Jan Skupień4, (D) Jerzy B. Starzyk2,3 \\ ${ }^{1}$ Hospital in Brzesko, Clinic of Pediatrics, Brzesko, Poland \\ 2Department of Pediatric and Adolescent Endocrinology, Chair of Pediatrics, Pediatric Institute, Jagiellonian University, Medical College, \\ Kraków, Poland \\ 3 University Children's Hospital of Kraków, Kraków, Poland \\ 4Jagiellonian University Medical College, Department of Metabolic Diseases, Kraków, Poland
}

What is already known on this topic?

An association between increase in body mass index-standard deviation score (BMI-SDS) and younger age of type 1 diabetes manifestation has been postulated. This is known as the accelerator hypothesis.

What this study adds?

An increase of type 1 diabetes incidence in the paediatric population of Lesser Poland was not associated with younger age of diagnosis, nor higher BMI-SDS.

\section{Abstract}

Objective: One of the hypothesized reasons for the observed increase in type 1 diabetes incidence in children is weight gain, causing accelerated disease development in predisposed individuals. This so-called accelerator hypothesis is, however, controversial. The aim was to analyze whether, in the ethnically homogeneous population of Lesser Poland, an increase in the number of cases of diabetes among children was associated with younger age and higher body mass index-standard deviation score (BMI-SDS) at the time of diagnosis.

Methods: Retrospective data analysis from medical records of all patients < 14 years $(n=559 ; 50.6 \%$ male), with newly diagnosed type 1 diabetes, in Lesser Poland between 1 st January 2006 and 31 st December 2017 (11 years).

Results: The incidence ratio ranged significantly $(p<0.001)$ from the lowest in $2006(11.2 / 100,000 / y e a r)$ to the highest in 2012 (21.9/100,000/year). The mean age of diagnosis was $8.2 \pm 3.5$ years. There was no trend in decreasing diagnosis age $(p=0.43)$. The mean BMI-SDS was $-0.4 \pm 1.2$. Almost all children (91.6\%) presented with BMI-SDS within the normal range at the time of diagnosis, with only $2.7 \%$ of cases being obese and $5.7 \%$ underweight at the moment of diagnosis. There was no clear trend at all in BMI-SDS over the study period.

Conclusion: These results do not corroborate an increase of type 1 incidence in paediatric population being associated with younger age of diagnosis and higher BMI-SDS. This implies that the accelerator hypothesis does not hold true in the study population.

Keywords: Accelerator hypothesis, body mass index, children, type 1 diabetes

\section{Introduction}

Type 1 diabetes is one of the most common chronic diseases in children and adolescents worldwide (1). Its increasing incidence, especially in industrially developed countries, makes it necessary to look for and define potential risk factors. Some recent studies point to a possible contribution of childhood overweight and obesity to the development of type 1 diabetes at a younger age $(2,3)$. Obesity is a
Address for Correspondence: Małgorzata Wójcik MD, Department of Pediatric and Adolescent Endocrinology, Chair of Pediatrics, Pediatric Institute, Jagiellonian University, Medical College; University Children's Hospital of Kraków, Kraków, Poland

Phone: +0048 123339039 E-mail: malgorzata.wojcik@uj.edu.pl ORCID: orcid.org/0000-0003-3889-1913

${ }^{\circ}$ Copyright 2020 by Turkish Pediatric Endocrinology and Diabetes Society

The Journal of Clinical Research in Pediatric Endocrinology published by Galenos Publishing House.
Conflict of interest: None declared Received: 20.08.2019 Accepted: 23.01.2020 
well-documented risk factor for type 2 diabetes, but there are some studies indicating an association between the increase of body weight in children and adolescents and the increase in the incidence rate of type 1 diabetes in these age groups $(2,3)$. That postulated association has been called the accelerator hypothesis $(3,4,5)$. One of the arguments for the existence of such a relationship is the fact that in countries where the incidence of type 1 diabetes is increasing in the younger age groups, a simultaneous increase in the incidence of obesity in the general pediatric population was found. The number of obese children and adolescents worldwide has increased tenfold in the last 40 years, and childhood obesity, defined as equal to or greater than the $95^{\text {th }}$ percentile of body mass index (BMI), has been recognized as an epidemic by the World Health Organization $(6,7)$. The accelerator hypothesis identifies three processes which may accelerate the apoptosis of pancreatic beta cells: constitution, insulin resistance and autoimmunity. According to that hypothesis, weight gain causes an increase in insulin resistance which leads to a deterioration in control of blood glucose level. The rising blood glucose level accelerates beta-cell apoptosis directly via glucotoxicity, and indirectly by inducing immunogenicity $(3,4,5,6,7,8)$. The authors of the accelerator hypothesis postulate that the pathogenesis of type 1 and type 2 diabetes may be, to some extent, similar and that overweight and insulin insufficiency are associated with both types of diabetes $(4,5)$. According to the hypothesis, excessive body weight in a child who is predisposed genetically to the development of type 1 diabetes accelerates the process of beta cell destruction leading to an earlier occurrence of an overt deficit of insulin $(3,6,8)$. This theory has been confirmed by some studies strongly supporting the association between BMI and earlier diagnosis of type 1 diabetes $(6,9,10,11)$. Nevertheless, it is not universally accepted, as there are other studies that have contradicted these findings and do not support such a relationship $(12,13,14,15)$. The starting point for the current study was a significant increase in the incidence of type 1 diabetes in the young age groups in the Lesser Poland region (from 5.2/100,000/year in 1987 to $21.9 / 100,000 /$ year in 2012), which was demonstrated in our previous paper (16). Simultaneously, there was evidence of an increase in obesity incidence in the general paediatric population over the same time period and in the same geographic area (17).

\section{Objective}

The aim of the study was to analyze whether, in the ethnically homogeneous population of Lesser Poland, an increase in the number of cases of diabetes among children was associated with younger age and higher BMI-standard deviation (SD) score (SDS) at the time of diagnosis.

\section{Methods}

Retrospective data was extracted from medical records of all patients under the age of 14 years, with newly diagnosed type 1 diabetes in the Krakow region (former województwo krakowskie) between 1 st of January 2006 and 31 st of December 2012 and in the whole of Lesser Poland between $1^{\text {st }}$ of January 2013 and 31 st of December 2017 and analyzed. The analysis included children with type 1 diabetes only; patients with other types of diabetes were excluded. Type 1 diabetes was defined as acute-onset diabetes presenting with ketoacidosis and/or symptoms of polyuria, polydipsia and weight loss, complete insulin dependence within $<1$ year from diagnosis, or positive anti-glutamic acid decarboxylase or anti-IA2 test on diabetes diagnosis. All data were collected in one centre for the region; the Department of Pediatric and Adolescents Endocrinology, Chair of Pediatrics, Jagiellonian University Medical College, which is the reference centre for the region.

Body weight and height were measured to the nearest $0.1 \mathrm{~kg}$ and $0.1 \mathrm{~cm}$, respectively, using a stadiometer (Harpenden, UK) and a balanced scale (Seca 700, Germany). All measurements were done during the hospitalization at the moment of diabetes diagnosis, after normalization of the general condition and rehydration. As the standard of reference for calculating BMI-SDS, normal values from the local population were used (18). Incidence rate was evaluated based on the data from the Central Statistical Office (Polish: Glowny Urzad Statystyczny) for the population of the region which was subject to analysis (19).

\section{Statistical Analysis}

Statistics data are presented as means with SD or medians and quartiles for continuous variables, or counts and percentages for categorical variables. Univariate and multiple regression models were used to test the association between BMI-SDS, age of diagnosis and calendar year of diagnosis. $P$ values $<0.05$ were considered significant. All calculations were performed using the Microsoft Excel and SAS 9.3 software.

\section{Ethics}

The study was conducted in accordance with the requirements of ethics, with particular regard to the protection of sensitive data. No additional consent from the bioethics committee was required due to the retrospective nature of the studies. Parents (legal guardians) and study 
participants gave informed consent for the later use of anonymised data.

\section{Results}

There were 559 (50.6\% male) cases of type 1 diabetes diagnosed before age 14 . The incidence ratio ranged significantly $(\mathrm{p}<0.001)$ from the lowest in 2006 (11.2/100,000/year) to the highest in $2012(21.9 / 100,000 /$ year) (Figure 1). The median (interquartile range) age of diagnosis was 8.4 (5.4 to 11.1) years, and the mean age was $8.2 \pm 3.5$ years. The mean BMI-SDS was $-0.4 \pm 1.2$, indicating type 1 diabetes onset in individuals somewhat leaner than the reference population. This reflects the weight loss characterizing the onset of diabetes. During the study period, there was no trend of decreasing age at the time of diagnosis (Figure 2, $\mathrm{p}=0.43$ ). Almost all children (91.6\%) presented with BMI-SDS within the normal range at the time of diagnosis, with only 16 (2.7\%) of cases being obese and $5.7 \%$ underweight at the moment of diagnosis (Table 1). There was no association between calendar year of diabetes diagnosis and BMI-SDS ( $p=0.87$, see Figure 3). A significant relationship was observed between the age of diabetes diagnosis and BMI-SDS. An increase in BMI-SDS by $1 \mathrm{SD}$ was associated with the development of the disease 0.54 years of age later (Figure 4) and this association remained unchanged after adjusting for sex and calendar year of diabetes diagnosis $(p<0.001)$. This association is the reverse of what would be expected from the accelerator hypothesis.

\section{Discussion}

The incidence of type 1 diabetes, as well as overweight and obesity in children are increasing in Poland $(13,17)$. The present study investigates whether these phenomena

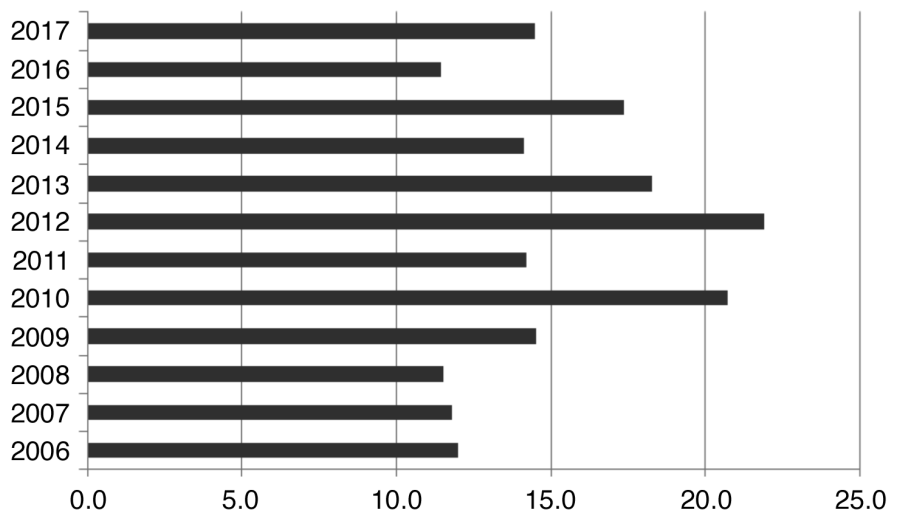

Figure 1. Incidence rates (per 100,000) for type 1 diabetes in Krakow and Lesser Poland region (Krakow only up to 2012 then figures represent the whole of Lesser Poland) are interrelated or only co-exist in the same time and place. This continuous and longitudinal study is the first such study conducted in our country. According to the current definitions, type 1 diabetes mellitus is an autoimmune chronic disease in children and adolescents determined by insulin insufficiency, while type 2 diabetes mellitus is a metabolic disorder in adults and the elderly population, associated with obesity and insulin resistance (13). The accelerator hypothesis attempts to unify both types of diabetes as the same insulin secretion disorder, but with a different background $(3,6,8)$. The rate of beta cell damage and insulin loss in type 1 diabetes seems to be associated with more susceptible genotypes and the influence of undefined environmental factors. To date there are more than 60 genomic loci identified, but human leukocyte antigen 6p21 has the strongest association with type 1 diabetes development, and islet autoimmunity develops in about $5 \%$ of people with that genetic predisposition $(19,20)$. Contrary to the welldefined genetic background, most of the environmental factors contributing to beta cell loss remain unidentified (21). One of the problems that has been investigated is the possible impact of overweight on the acceleration of insulin insufficiency. In recent years, many trials have been conducted to prove this theory. Studies conducted in different ethnic settings worldwide reported conflicting results (inverse, positive or lack of correlation between body weight and the development of type 1 diabetes). A Norwegian cohort study pointed to an increased risk

Table 1. The occurrence of obesity (body mass indexstandard deviation score $>2.0$ ) in patients with newly diagnosed type 1 diabetes in sequencial years of observation

\begin{tabular}{ll}
\hline Year & $\begin{array}{l}\text { Number of patients with obesity } \\
\text { (BMI-SDS > 2.0) } \\
\text { (number of all newly diagnosed type } 1 \\
\text { diabetes cases) }\end{array}$ \\
\hline 2006 & $0[21]$ \\
2007 & $1[20]$ \\
2008 & $2[21]$ \\
2009 & $0[22]$ \\
2010 & $0[23]$ \\
2011 & $0[27]$ \\
2012 & $0[22]$ \\
2013 & $5[97]$ \\
2014 & $1[75]$ \\
2015 & $2[92]$ \\
2016 & $1[61]$ \\
2017 & $4[78]$ \\
\hline
\end{tabular}

BMI-SDS: body mass index-standard deviation score 
of autoimmunity in individuals with high-risk genotype with a weight gain of over $15 \mathrm{~kg}$ within the first year of life and/or maternal BMI during pregnancy over 30 $\mathrm{kg} / \mathrm{m}^{2}$ (19). Even stronger evidence supporting the accelerator hypothesis was provided by the Southeastern Wisconsin study that revealed a significant inverse correlation between BMI and age of diagnosis (9). In a European study, Knerr et al (10) also demonstrated that elevated BMI has an impact on younger age of diabetes onset. Slightly more cautious conclusions were drawn from the study by Dabelea et al (11) that indicated an inverse correlation but only in children with already reduced beta cell function indicated by fasting $\mathrm{C}$-peptide level below the median. In our study, we did not confirm an association between higher BMI-SDS and age at the moment of diagnosis. Indeed, in younger children there was a small association in the opposite direction. Similar observations were also made by authors investigating this phenomenon in various parts of the world. Over 20 years

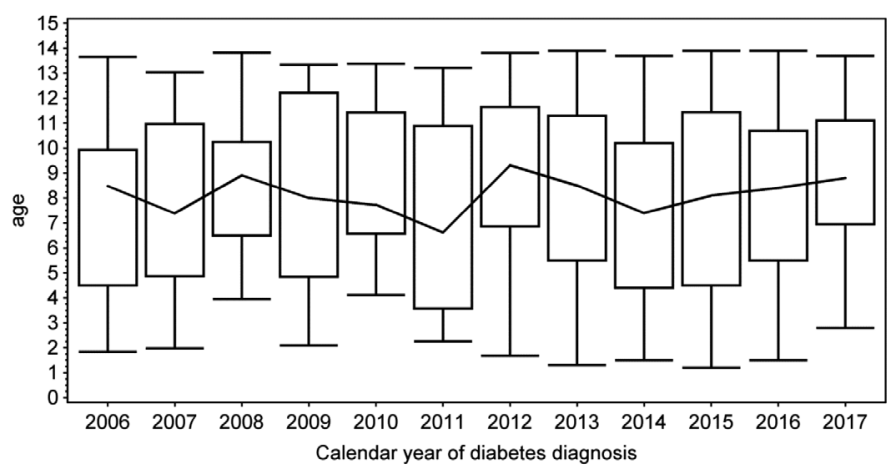

Figure 2. Box plot of mean age at the time of type 1 diabetes diagnosis in sequencially analyzed calendar years. The upper and lower box boundaries indicate quartiles and the line across the centre of the graph joins the medians. The whiskers indicate the range of age in each year

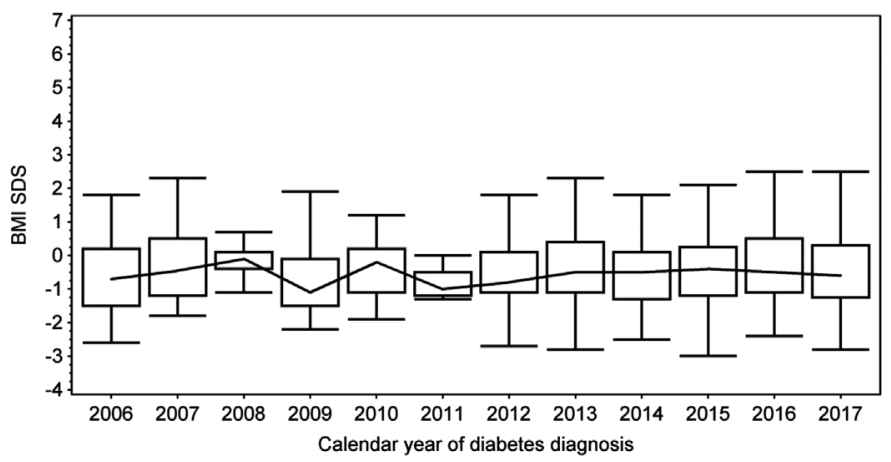

Figure 3. Box plot of mean age at the time of type 1 diabetes diagnosis in sequencially analyzed calendar years. The upper and lower box boundaries indicate quartiles and the line across the centre of the graph joins the medians. The whiskers indicate the range of age in each year

BMI-SDS: Body mass index-standard deviation score of observation of Australian children under 16 years of age with type 1 diabetes, Islam et al (13) reported that the number of overweight and obese children has remained relatively stable, despite an increase in the incidence rate of type 1 diabetes. Moreover, Derraik et al (12) showed that the mean BMI-SDS of newly diagnosed type 1 diabetes over the period 1990-2009 in New Zealand did not alter in comparison to the general population. Also in our group the incidence of obesity at the moment of type 1 diabetes diagnosis was comparable to the general population living in the same geographic area (17). The prevalence of overweight and obesity is not regulary screened among Polish children. There is no national registry, therefore the precise, reliable data is not available. Nevertheless, in recent years several studies have been published on the prevalence of overweight and obesity in children and adolescents living in different regions of Poland. However, mainly due to differences in research methodology, their results are quite divergent. For example, in Gdańsk, in the North of Poland, obesity was found in 1.5-7.5\% of subjects, depending on sex and age at the time of the study (22). In a study conducted among seven-year-olds in a city of Wrocław, in Lower Silesia, South-Western Poland, obesity was found to vary between 10.7-26.6\% of children, depending on the place of residence (23). In South-Eastern Poland in 2012, the prevalence of obesity in preschool children was $10.8 \%$ (24). In the region covered by our study, the prevalence of obesity in adolescents aged between 14-18 years old is $4.2 \%$ (17). To some extent the prevalence of excess weight may be obscured by the fact that anthropometric measurement were taken

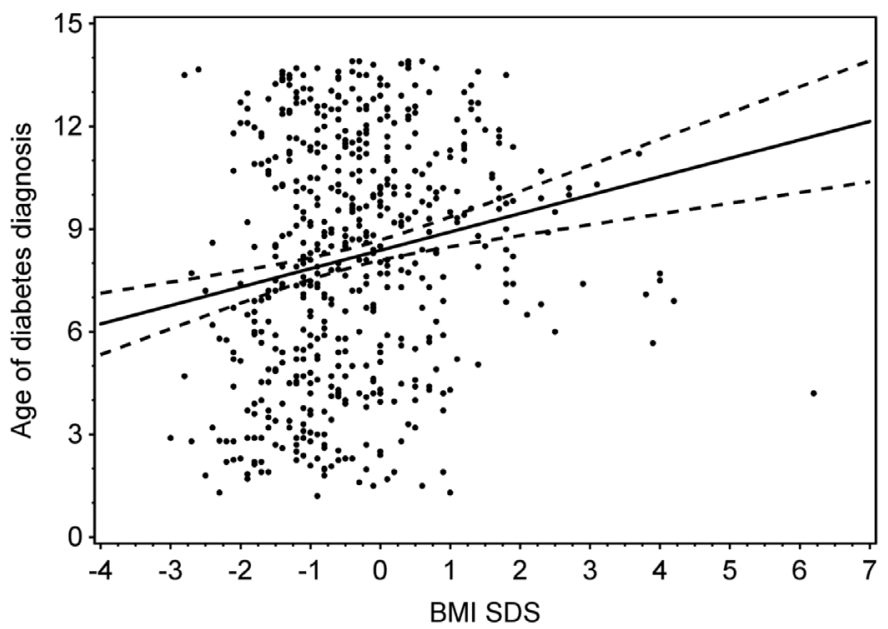

Figure 4. Box plot of mean body mass index-standard deviation score (BMI-SDS) at the time of type 1 diabetes diagnosis in sequencially analyzed calendar years. The upper and lower box boundaries indicate quartiles and the line across the centre of the graph joins the medians. The whiskers indicate the range of BMI-SDS in each year 
at diabetes diagnosis. The effect of dehydration may be ruled out, but some degree of loss of body mass has persisted at that time. That is an undoubted limitation of this study, as well as other similar papers. All the weight measurement took place after the diagnosis of the disease on the basis of clinical symptoms. Although the body weight values analyzed came from measurements made after rehydration, resolution of acidosis and improvement of general condition, they cannot take into account the full weight loss associated with lypolysis of adipose tissue before the onset of diabetes. In fact, such an analysis is not possible, because in the first phase type 1 diabetes occurs without clinically overt symptoms and it is not possible to accurately determine its onset, and thus accurate determination of BMI-SDS at the time of actual onset of the disease is also not possible. We were unable to use body weight from before diabetes onset, as regular and standardized measurement were never taken on regular basis in healthy children. Since weight loss would affect all study subjects, we do not expect that this issue has altered the relationships between age of diabetes diagnosis and BMI-SDS. Recently published data from over 360,000 British children and young adults ( $<25$ years old) observed during 1994-2013 did not show any significant correlation between BMI and type 1 diabetes incidence. Interestingly, the authors pointed to a slightly higher incidence rate in overweight, but not in obese children (14). Attempts to include additional ethnic factors showed that the accelerator hypothesis is not universal (15). Interestingly, we found that BMISDS was significantly higher in the older age groups. An increase in BMI-SDS by 1 SD was associated with the development of the disease 0.54 years of age later. This novel observation seems to be particularly important if we take into consideration the possible impact of puberty on insulin secretion. The relationship between obesity, puberty and type 2 diabetes incidence is clear and well documented (25). During puberty, growth hormone and cortical secretion increases, causing physiological insulin resistance (2). Therefore type 2 diabetes almost never occurs in children before puberty. Our results point to a potential contribution of increased body weight during puberty on the age of type 1 diabetes manifestation. Perhaps, the accelerator hypothesis may therefore partly explain the incidence of type 1 diabetes in the period of puberty. However, this would be very difficult to prove but warrants further investigation.

\section{Study Limitations}

The main limitation of our study is the inclusion of a relatively small group of participants. However, taking into consideration that we analyzed all new cases of type 1 diabetes under the age of 14 in the homogeneous Lesser Poland population, the results can be considered valuable. To obtain more reliable data, it would be advisable to perform a similar analysis for a national cohort or, optimally, a multinational study.

\section{Conclusion}

These results do not corroborate an increase of type 1 incidence in a paediatric population being associated with younger age of diagnosis and higher BMI-SDS. This implies that the accelerator hypothesis does not hold true in the studied population.

\section{Ethics}

Ethics Committee Approval: Ethics committee approval was not necessary for this kind of study, which was an analysis of anonymous retrospective data from Children's University Hospital database.

Informed Consent: Parents (legal guardians) and study participants gave informed consent for the later use of anonymised data.

Peer-review: Externally and internally peer-reviewed.

\section{Authorship Contributions}

Concept: Barbara Wasyl-Nawrot, Małgorzata Wójcik, Design: Barbara Wasyl-Nawrot, Małgorzata Wójcik, Data Collection or Processing: Barbara Wasyl-Nawrot, Małgorzata Wójcik, Analysis or Interpretation: Jan Skupień, Małgorzata Wójcik, Literature Search: Barbara Wasyl-Nawrot, Małgorzata Wójcik, Writing: Barbara Wasyl-Nawrot, Małgorzata Wójcik, Jan Skupień, Joanna Nazim, Jerzy B. Starzyk.

Financial Disclosure: The authors declared that this study received no financial support.

\section{References}

1. Craig ME, Jefferies C, Dabelea D, Balde N, Seth A, Donaghue KC, International Society for Pediatric and Adolescent Diabetes. Clinical Practice Consensus Guidelines 2014. Definition, epidemiology, diagnosis and classification. Pediatric Diabetes 2014;15(Suppl 20):417 .

2. Pulgaron ER, Delamater AM. Obesity and type 2 diabetes in children: epidemiology and treatment. Curr Diab Rep 2014;14:508.

3. Wilkin TJ. The accelerator hypothesis: weight gain as the missing link between Type I and Type II diabetes. Diabetologia 2001;44:914 922.

4. Wilkin TJ. The convergence of type 1 and type 2 diabetes in childhood: the accelerator hypothesis. Pediatr Diabetes 2012;13:334-339.

5. Wilkin TJ. Diabetes: 1 and 2, or one and the same? Progress with the accelerator hypothesis. Pediatr Diabetes 2008;9:23-32. 
6. Betts $\mathrm{P}$, Mulligan J, Ward $\mathrm{P}$, Smith $\mathrm{B}$, Wilkin T. Increasing body weight predicts the earlier onset of insulin-dependent diabetes in childhood: testing the 'accelerator hypothesis' (2). Diabet Med 2005;22:144-151.

7. NCD Risk Factor Collaboration (NCD-RisC). Worldwide trends in body-mass index, underweight, overweight, and obesity from 1975 to 2016: a pooled analysis of 2416 population-based measurement studies in 128.9 million children, adolescents, and adults. Lancet 2017;390:2627-2642.

8. Wilkin T, Greene S, McCrimmon R. Testing the accelerator hypothesis: a new approach to type 1 diabetes prevention (ad APT 1). Diabetes Obes Metab 2016;18:3-5.

9. Evertsen J, Alemzadeh R, Wang X. Increasing incidence of pediatric type 1 diabetes mellitus in Southeastern Wisconsin: relationship with body weight at diagnosis. PLoS One 2009;4:e6873.

10. Knerr I, Wolf J, Reinehr T, Stachow R, Grabert M, Schober E, Rascher W, Holl RW, DPV Scientific Initiative of Germany and Austria. The 'accelerator hypothesis': relationship between weight, height, body mass index and age at diagnosis in a large cohort of 9,248 German and Austrian children with type 1 diabetes mellitus. Diabetologia 2005;48:2501-2504.

11. Dabelea D, D’Agostino RB Jr, Mayer-Davis EJ, Pettitt DJ, Imperatore G, Dolan LM, Pihoker C, Hillier TA, Marcovina SM, Linder B, Ruggiero AM, Hamman RF. Testing the accelerator hypothesis: body size, beta-cell function, and age at onset of type 1 (autoimmune) diabetes. Diabetes Care 2006;29:290-294.

12. Derraik JG, Reed PW, Jefferies C, Cutfield SW, Hofman PL, Cutfield WS Increasing incidence and age at diagnosis among children with type 1 diabetes mellitus over a 20-year period in Auckland (New Zealand). PLoS One 2012;7:e32640.

13. Islam ST, Abraham A, Donaghue KC, Chan AK, Lloyd M, Srinivasan S, Craig ME. Plateau of adiposity in Australian children diagnosed with Type 1 diabetes: a 20-year study. Diabet Med 2014;31:686-690.

14. Abbasi A, Juszczyk D, van Jaarsveld CHM, Gulliford MC. Body Mass Index and Incident Type 1 and Type 2 Diabetes in Children and Young Adults: A Retrospective Cohort Study J Endocr Soc 2017;1:524-537.

15. Channanath AM, Elkum N, Al-Abdulrazzaq D, Tuomilehto J, Shaltout A, Thanaraj TA. Ethnic differences in association of high body mass index with early onset of Type 1 diabetes- Arab ethnicity as case study PLoS One 2017;12:e0175728.

16. Wojcik M, Sudacka M, Wasyl B, Ciechanowska M, Nazim J, Stelmach M, Starzyk JB. Incidence of type 1 diabetes mellitus during 26 years of observation and prevalence of diabetic ketoacidosis in the later years. Eur J Pediatr 2015;174:1319-1324. Epub 2015 Apr 17

17. Klimek-Piotrowska W, Koziej M, K. Hołda M, Piątek K, Wszołek K, Tyszka A, Kmiotek E, Pliczko M, Śliwińska A, Krauss K, Miszczyk M, Walocha J. Anthropometry and body composition of adolescents in Cracow, Poland. PLoS One 2015;10:e0122274.

18. Palczewska I, Niedzwiecka Z. Wskazniki rozwoju somatycznego dzieci i młodziezy warszawskiej. (Somatic development indices in children and youth of Warsaw). Med Wieku Rozwoj 2001;5:18-118.

19. Główny Urząd Statystyczny. Last accessed date: 14.08.2020. Available from: https://bdl.stat.gov.pl/BDL/start

20. Islam ST, Srinivasan S, Craig ME. Environmental determinants of type 1 diabetes: a role for overweight and insulin resistance. J Paediatr Child Health 2014;50:874-879.

21. Wilkin TJ. Testing the accelerator hypothesis: body size, beta-cell function, and age at onset of type 1 (autoimmune) diabetes: response to Dabelea et al. Diabetes Care 2006;29:1462-1463; author reply: 1463-1464.

22. Brzeziński M, Jankowski M, Jankowska A, Niedzielska A, Kamińska B. Is there a rapid increase in prevalence of obesity in Polish children? An 18-year prospective observational study in Gdansk, Poland. Arch Med Sci 2018;14:22-29. Epub 2017 Dec 19

23. Czajka K. Comparison of the prevalence of body mass disorders in 7-year-old children living in rural and urban areas of Lower Silesia in Poland. Rocz Panstw Zakl Hig 2019;70:147-153.

24. Łuszczki E, Dereń K, Baran J, Weres A, Mazur A. Trend sekularny występowania nadwagi i otyłości wśród dzieci w przedszkolach regionu rzeszowskiego. Endokrynol. Pediatryczna 2015;14:29-34.

25. Hannon TS, Rao G, Arslanian SA. Childhood obesity and type 2 diabetes mellitus. Pediatrics. Pediatrics 2005;116:473-480. 